\title{
Proton MRS and quantitative MRI assessment of the short term neurological response to antiretroviral therapy in AIDS
}

Iain D Wilkinson, Sarah Lunn, Katherine A Miszkiel, Robert F Miller, Martyn N J Paley, Ian Williams, Roger J S Chinn, Margaret A Hall-Craggs, Stanton P Newman, Brian E Kendall, Michael J G Harrison

Department of

Medical Physics and

Bioengineering, The

Middlesex Hospital,

University College

London Hospitals NHS

Trust, Mortimer

Street, London

I D Wilkinson

Department of

Psychiatry, University

College London

Medical School,

London

S Lunn

S P Newman

Department of Radiology, The Middlesex Hospital,

University College

London Hospitals NHS

Trust, Mortimer

Street, London

K A Miszkiel

R J S Chinn

M A Hall-Craggs

B E Kendall

Division of Pathology and Infectious

Diseases, University

College London

Medical School,

London

R F Miller

I Williams

Department of

Neurology, University

College London

Medical School,

London

M N J Paley

M J G Harrison

Correspondence to: Dr Iain Wilkinson, MRI

Umit, The Middlesex

Hospital, Mortimer Street,

London W1N 8AA, UK.

Received 2 December 1996 and in revised form 14 March 1997

Accepted 2 May 1997

\begin{abstract}
Objective-To investigate MRI and proton spectroscopy changes in five patients with HIV associated dementia complex (HADC) treated with antiretroviral therapy.

Methods-Three markers were evaluated: (1) CSF/intracranial volume ratio; (2) T2 weighted signal ratio between parietooccipital white and subcortical grey matter; and (3) metabolite ratios from long echo time ( $T E=135 \mathrm{~ms}$ ) single voxel proton spectra of parieto-occipital white matter.

Results-Spectroscopic changes indicated initial increases in $\mathbf{N}$-acetyl/(N-acetyl + choline + creatine) ratio (NA/NA+ Cho+Cr)) and progression of atrophy after initiation of antiretroviral therapy in four of five patients. When the neurological status of the patients subsequently deteriorated (two of five patients), the $\mathrm{NA} /(\mathrm{NA}+\mathrm{Cho}+\mathrm{Cr})$ ratio also declined. Conclusions-spectroscopic changes mirror reversible neuronal dysfunction. These objective, non-invasive techniques may be used for monitoring the neurological effects of antiretroviral drug therapy in patients with HADC.
\end{abstract}

(F Neurol Neurosurg Psychiatry 1997;63:477-482)

Keywords: magnetic resonance spectroscopy; human immunodeficiency virus; zidovudine

One of the more common neurological complications of HIV infection is HIV associated dementia complex (HADC), also known as HIV-1 associated cognitive/motor complex. The pathogenesis of HADC is thought to be directly linked to HIV itself rather than to secondary opportunistic infection or malignancy. The prominent clinical features of HADC are a disabling cognitive impairment, often accompanied by motor dysfunction and behavioural change. ${ }^{1}$ In addition to clinical evaluation and psychometric testing there is a need for objective methods to monitor progression in HADC and response to treatment.

Common findings on T2 weighted MRI in patients with HADC are the presence of diffuse or patchy hyperintensity within the cerebral white matter with or without atrophy. ${ }^{2-4} \mathrm{~A}$ qualitative description of partial resolution of white matter hyperintensity on MRI has been reported in a few cases after treatment with antiretroviral agents. ${ }^{5}$ These data suggest that changes in cognitive function after therapy could be monitored in a non-subjective manner by quantitative imaging techniques. Such techniques have been developed to quantitatively assess the degree of diffuse cranial MRI abnormalities associated with HIV infection, which provide a semiautomated measure of white matter changes and atrophy. ${ }^{67}$

Using proton magnetic resonance spectroscopy (MRS) of white matter, abnormalities of brain metabolites have been documented in patients with HADC..$^{8-10}$ These spectroscopic abnormalities, especially those acquired at short echo and long repetition times, ${ }^{11} 12$ imply reductions in the levels of the $\mathrm{N}$-acetyl (NA) resonances, the main constituent of which is $\mathrm{N}$-acetyl aspartate, a group largely confined to neurons. Pathological evidence supports the inferred reduction in neuronal density in the brains of patients with AIDS. ${ }^{13}$ Two recent reports have documented the reversal of abnormal proton spectroscopic brain metabolites at long echo times (TE=135 ms) concomitant with clinical improvement after antiretroviral therapy, ${ }^{14}{ }^{15}$ suggesting that the NA resonance may be a marker of integrity of neuronal function rather than simply neuronal death.

This paper presents quantitative imaging and spectroscopic findings in five patients with HADC who underwent MRI and MRS examinations before and during treament with antiretroviral drugs. The main aims were firstly to quantify the presence of parenchymal atrophy using the cluster localised automated spherical segmentation (CLASS) technique; ${ }^{7}$ secondly to quantitate abnormalities of diffuse white matter by evaluation of white/grey matter pixel intensity ratios, ${ }^{6}$ and, thirdly to evaluate the relative concentrations of cerebral metabolites in white matter by single voxel proton spectroscopy. ${ }^{9}$ Results of the MR examinations were compared with the clinical status of the patients before and during therapy.

\section{Methods}

Five homosexual men with HIV infection were studied before and during treatment with the antiretroviral drug zidovudine (AZT, GlaxoWellcome PLC, Beckenham, UK). All five patients were zidovudine naive at the start of 
Table 1 Clinical characteristics of the five patients at the time of their first MR examination

\begin{tabular}{lllc}
\hline Patient No & Age $(y)$ & $\begin{array}{l}\text { Previous AIDS defining diagnosis (CDC group } \\
\left.I V^{\star}\right)\end{array}$ & CD4 count $+\times 10^{6} / l$ \\
\hline 1 & 34 & Pneumocystis carinii pneumonia & 20 \\
2 & 29 & None & 360 \\
3 & 34 & Oesophageal candidiasis & $<10$ \\
4 & 54 & None & 20 \\
5 & 34 & Pulmonary tuberculosis & 180
\end{tabular}

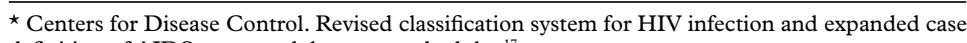
definition of AIDS among adolescents and adults. ${ }^{17}$

† Normal range $=350-2200 \times 10^{6} / 1$.

this study and had presented with a subacute encephalopathy consistent with a diagnosis of $\mathrm{HADC}^{16}$ confirmed both by clinical evaluation and by psychometric testing. All patients were still on zidovudine treatment at the time of their final MRI. Table 1 shows the patients' ages, CD4 lymphocyte counts (measured within three months of the first MR examination), and previous AIDS defining diagnoses. ${ }^{17}$

In three patients $(1,3$, and 5) CSF analysis was performed at the time of the first MR examination. At lumbar puncture CSF samples were negative for cytomegalovirus and herpes simplex virus type 1 DNA by polymerase chain reaction amplification ${ }^{18}$ and fungi, bacteria, and mycobacteria by culture. At necropsy in patient 2 there was no pathological evidence of cytomegalovirus encephalitis.

MR data were obtained using a standard clinical system (Siemens 63SP, Erlangen, Germany) operating at $1.5 \mathrm{~T}$. Images were acquired using a dual spin echo sequence $(\mathrm{TR}=3500$ $\mathrm{ms}, \mathrm{TE}=20 / 90 \mathrm{~ms}, \mathrm{Acq}=1$, matrix $=192 \times 256$, $\mathrm{FOV}=23 \mathrm{~cm}$ ) which produced 30 contiguous 5 $\mathrm{mm}$ slices. The image plane was parallel to the long axis of the temporal lobes, enabling complete coverage of the cranium. These images were used for white/grey matter pixel intensity ratio and volume calculations. Before acquisition of spectroscopy data, a further set of axial dual spin echo images $(\mathrm{TR}=1800 \mathrm{~ms}, \mathrm{TE}=20$ / $90 \mathrm{~ms}, \mathrm{Acq}=1$, matrix $=128 \times 256, \mathrm{FOV}=23 \mathrm{~cm}$ ) with a reduced slice thickness of $3 \mathrm{~mm}$ were acquired to enable accurate positioning of the spectroscopic region of interest (ROI). Spectroscopic data were acquired using a single voxel, spin echo sequence (TR=1600 ms, $\mathrm{TE}=135 \mathrm{~ms}, \mathrm{Acq}=256$ ) applied to a $2 \times 2 \times 2 \mathrm{~cm}$ ROI placed within parieto-occipital white matter, as previously reported. ${ }^{9}$ Care was taken in placing the spectroscopic ROI as close as possible to the initial anatomical location during follow up investigations.

VOLUME CALCULATIONS

Cerebrospinal fluid/intracranial volume $(\mathrm{CSF} /$ ICV) ratios were calculated from the dual echo images using the CLASS technique, a detailed description of which, including associated measurement errors, is given elsewhere. ${ }^{7}$ In brief, this technique reduced two dimensional pixel data from the dual spin echo proton density and $\mathrm{T} 2$ weighted images to a one dimensional histogram, for each image slice through the brain. Threshold values within this histogram were then used to discriminate between noise, CSF, and brain parenchyma.
The number of pixels corresponding to CSF and brain parenchyma were given by the areas under the peaks on the one dimensional histogram which corresponded to these substances and as the pixel dimensions and slice thickness were known, the absolute volumes of CSF and brain parenchyma could be calculated. This calculation was repeated for each of the 30 contiguous slices which cover the cranium. To normalise between differences in intersubject head sizes, the results were expressed in terms of the ratio:

$\mathrm{CSF} / \mathrm{ICV}=\mathrm{CSF}$ volume $/(\mathrm{CSF}$ volume + brain parenchyma volume)

WHITE/GREY MATTER PIXEL INTENSITY RATIOS A full description of the technique used to quantify diffuse abnormalities within the deep white matter complete with a discussion of the associated subject and observer related measurement errors has been previously presented. ${ }^{6}$ In summary, white matter within the parieto-occipital region (POWM) and grey matter within the head of the caudate nuclei (HCGM) were sampled in both hemispheres on the T2 weighted images, using circular regions of interest. The white and grey matter regions contained 129 and 21 pixels respectively. Results were expressed as the ratio (Cwg) between the white and grey matter pixel intensities:

$\mathrm{Cwg}=\left(\mathrm{POWM}_{1}+\mathrm{POWM}_{\mathrm{r}}\right) /$

$\left(\mathrm{HCGM}_{1}+\mathrm{HCGM}_{\mathrm{r}}\right)$

where ${ }_{1}$ and ${ }_{\mathrm{r}}$ denote left and right hemispheres. The ratio of pixel intensities was used to eliminate errors bought about by variations in machine set up over time.

PROTON SPECTROSCOPY

After eddy current correction, mild gaussian filtering $(4 \mathrm{~Hz})$, and Fourier transformation, the areas under the three main peaks (NA resonances at $2.02 \mathrm{ppm}$, creatine resonances (Cr) at $3.03 \mathrm{ppm}$, and choline resonances (Cho) at $3.22 \mathrm{ppm}$ ) were calculated by direct numerical integration. Results were expressed as the ratios between these areas: NA/Cho; $\mathrm{NA} / \mathrm{Cr}$; Cho/Cr, and NA/(NA+Cho+Cr).

All MR data from the five HIV seropositive patients were compared with the means from a control group which consisted of $17 \mathrm{HIV}$ seronegative homosexual men at high risk for HIV infection (mean age $=40$ (SD 9) years, range $=27-61$ years $)$.

\section{Results}

Table 2 shows the results of the MR investigations together with the timing of the scans relative to initiation of zidovudine and an assessment of the clinical neurological status of each of the patients at the time of their scans. The figure shows proton spectra, segmented transverse images, and T2 weighted transverse images for patient 1 .

ASSESSMENT OF ATROPHY

Before the start of therapy, one of five patients had a CSF/ICV ratio $>2$ SD above the mean of the control group (patient 5) although four of 
Table 2 Metabolite ratios, white/grey matter ratios, and CSF to intracranial volume ratios for the five patients. Means (SD) from the seronegative high risk control group are also given. Time = Time relative to the commencement of antiretroviral therapy

\begin{tabular}{|c|c|c|c|c|c|c|c|c|}
\hline & Time (weeks) & $N A /(N A+C h o+C r)$ & $\mathrm{NA} / \mathrm{Cr}$ & NA/Cho & $\mathrm{Cho} / \mathrm{Cr}$ & $C_{v g}$ & $C S F / I C V$ & HADC status * \\
\hline Patient 1 & $\begin{array}{r}-7.6 \\
8.7 \\
20.1\end{array}$ & $\begin{array}{l}0.42 \\
0.54 \\
0.40\end{array}$ & $\begin{array}{l}1.72 \\
2.29 \\
1.48\end{array}$ & $\begin{array}{l}1.26 \\
2.39 \\
1.23\end{array}$ & $\begin{array}{l}1.36 \\
0.96 \\
1.20\end{array}$ & $\begin{array}{l}1.02 \\
1.02 \\
0.93\end{array}$ & $\begin{array}{l}0.15 \\
0.17 \\
0.18\end{array}$ & $\begin{array}{l}- \\
\text { Improvement } \\
\text { Deterioration }\end{array}$ \\
\hline Patient 2 & $\begin{array}{r}0.0 \\
3.8 \\
15.2\end{array}$ & $\begin{array}{l}0.31 \\
0.47 \\
0.41\end{array}$ & $\begin{array}{l}1.00 \\
1.96 \\
1.72\end{array}$ & $\begin{array}{l}0.81 \\
1.68 \\
1.19\end{array}$ & $\begin{array}{l}1.23 \\
1.17 \\
1.44\end{array}$ & $\begin{array}{l}1.11 \\
1.08 \\
1.13\end{array}$ & $\begin{array}{l}0.18 \\
0.22 \\
0.23\end{array}$ & $\begin{array}{l}- \\
\text { Improvement } \\
\text { Deterioration }\end{array}$ \\
\hline Patient 3 & $\begin{array}{l}-2.0 \\
-0.8 \\
13.2\end{array}$ & $\begin{array}{l}0.45 \\
0.46 \\
0.52\end{array}$ & $\begin{array}{l}1.78 \\
1.64 \\
2.16\end{array}$ & $\begin{array}{l}1.52 \\
1.71 \\
2.16\end{array}$ & $\begin{array}{l}1.17 \\
0.96 \\
1.00\end{array}$ & $\begin{array}{l}1.00 \\
1.03 \\
0.89\end{array}$ & $\begin{array}{l}0.18 \\
0.19 \\
0.24\end{array}$ & $\begin{array}{l}- \\
\overline{\text { Improvement }}\end{array}$ \\
\hline Patient 4 & $\begin{array}{r}-0.3 \\
6.7\end{array}$ & $\begin{array}{l}0.55 \\
0.51\end{array}$ & $\begin{array}{l}2.30 \\
2.42\end{array}$ & $\begin{array}{l}2.56 \\
1.77\end{array}$ & $\begin{array}{l}0.90 \\
1.37\end{array}$ & $\begin{array}{l}1.34 \\
1.45\end{array}$ & $\begin{array}{l}0.12 \\
0.13\end{array}$ & Improvement \\
\hline Patient 5 & $\begin{array}{r}-0.1 \\
4.7\end{array}$ & $\begin{array}{l}0.44 \\
0.51\end{array}$ & $\begin{array}{l}1.59 \\
2.20\end{array}$ & $\begin{array}{l}1.52 \\
1.94\end{array}$ & $\begin{array}{l}1.05 \\
1.13\end{array}$ & $\begin{array}{l}0.93 \\
0.94\end{array}$ & $\begin{array}{l}0.22 \\
0.26\end{array}$ & No changet \\
\hline Controls $(\mathrm{n}=17)($ mean $(\mathrm{SD}))$ & - & $0.54(0.04)$ & $2.31(0.49)$ & $2.58(0.68)$ & $0.94(0.27)$ & $0.93(0.05)$ & $0.13(0.03)$ & - \\
\hline
\end{tabular}

^ Degree of HADC (HIV associated dementia complex) relative to that at the time of the initial scan.

† Patient improved clinically after the addition of lamivudine (3TC, GlaxoWellcome PLC, Beckenham, UK) to treatment regimen 4.7 weeks after the final scan.

A

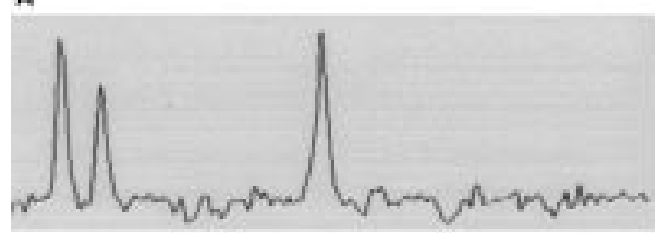

B

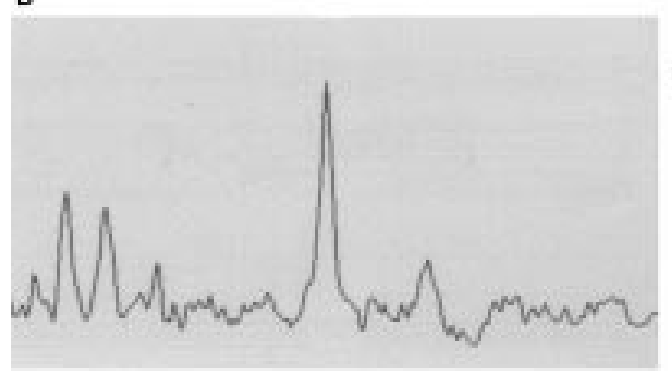

C

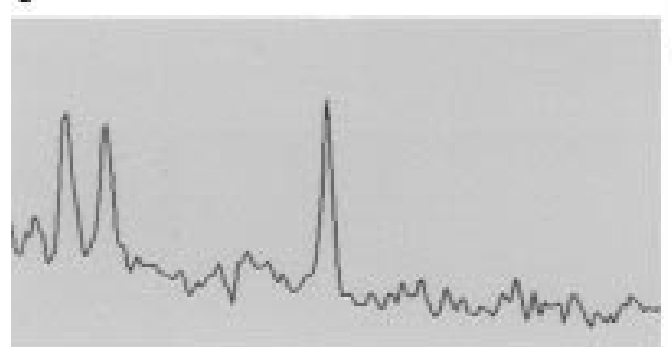

3.23 .0282 .62 .42 .2201 .81 .61 .412 .000 .80 .6

Chemical shift (ppm)
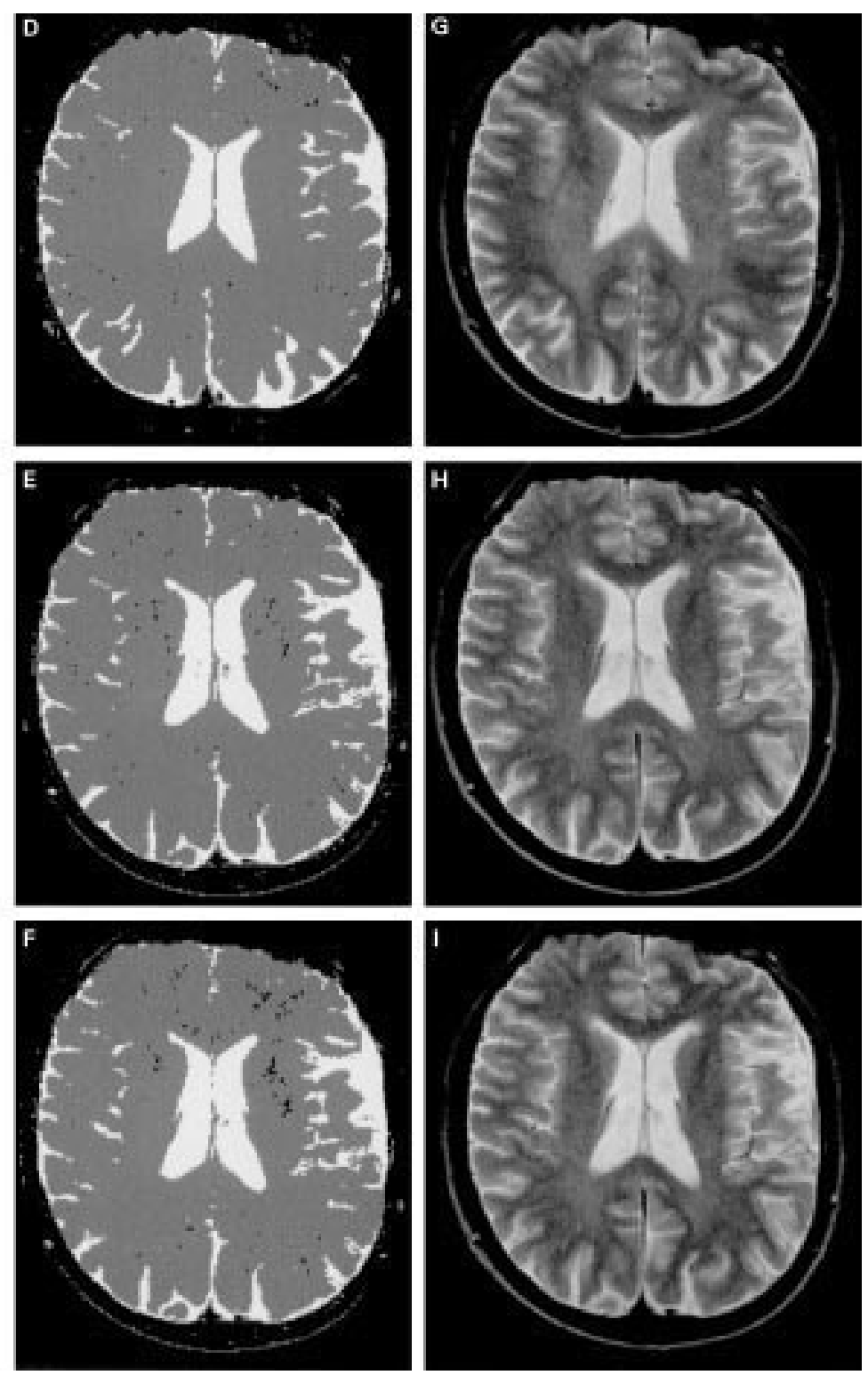

Data from patient $1(A-C)$ Proton spectra from an $8 \mathrm{ml}$ cube of parietooccipital white matter; $(D-F)$ segmented transverse images (grey = brain parenchyma, white $=C S F) ;(G-I)$ T2 weighted $(T R=3500 \mathrm{~ms}, T E=80 \mathrm{~ms})$ transverse images at the same level as the segmented images. Each of the three data sets correspond to $(A, D, G) 7.6$ weeks before initiation of zidovudine therapy, $(B, E, H)$ after 8.7 weeks, and (C, F, I) 20.1 weeks of therapy. 
five patients had a ratio greater than the mean of the control group at this time (patients 1,2 , $3,5)$. During therapy with zidovudine, the $\mathrm{CSF} / \mathrm{ICV}$ ratio increased in all five patients irrespective of clinical response and in three of five patients the degree of atrophy progressed to a $\mathrm{CSF} / \mathrm{ICV}$ ratio $>2 \mathrm{SD}$ above the mean of the control group (patients 2, 3 and 5). It is worth noting that the increase in $\mathrm{CSF} / \mathrm{ICV}$ ratio in patient 4 was small compared with the $\mathrm{SD}$ in $\mathrm{CSF} / \mathrm{ICV}$ ratio of the control group.

ASSESSMENT OF ABNORMALITY OF WHITE MATTER In two out of the five patients (2 and 4) Cwg was $>2$ SD above the mean of the control group, before the start of therapy. In two of five patients (2 and 3), Cwg decreased or increased respectively as patients neurologically improved or deteriorated. In patients 1 and 5, there were no large changes in $\mathrm{Cwg}$ as the patients' neurological status improved. However, Cwg did decrease in patient 1 but this decrease lagged behind the initial clinical improvement. Only patients 3 and 4 showed changes in Cwg which were greater than $2 \mathrm{SD}$ of the control group. In patient 4, whose initial Cwg was much higher than the mean of the control data, this large increase in $\mathrm{Cwg}$ occurred despite clinical improvement.

SPECTROSCOPIC METABOLITE RATIOS

Before the start of therapy, the NA/ $(\mathrm{NA}+\mathrm{Cho}+\mathrm{Cr})$ ratio was $>2 \mathrm{SD}$ below the mean of the control group in all but patient 4 . In patient 4 , the initial $\mathrm{NA} /(\mathrm{NA}+\mathrm{Cho}+\mathrm{Cr})$ ratio was higher than the mean of the control group, despite the clinical diagnosis of HADC. The $\mathrm{NA} /(\mathrm{NA}+\mathrm{Cho}+\mathrm{Cr})$ ratio increased after initiation of drug therapy in all but one patient (4). Patient 5 showed an increase in NA/ $(\mathrm{NA}+\mathrm{Cho}+\mathrm{Cr})$ despite having no initial clinical response to therapy. In patients 1 and 2, who deteriorated clinically between their second and third scans, the $\mathrm{NA} /(\mathrm{NA}+\mathrm{Cho}+\mathrm{Cr})$ ratio concomitantly decreased.

\section{Discussion}

The most important finding in this study was the ability of proton MRS to mirror clinical improvement after initiation of therapy (patients 1,2, and 3) and to subsequently mirror clinical deterioration (patients 1 and 2). Reversal in spectroscopic abnormalities after antiretroviral therapy in patients with AIDS has previously been reported $^{14}{ }^{15}$ and the findings were in agreement with this study. A previous report from our group showed a coefficient of variation of $2 \%$ in $\mathrm{NA} /$ $(\mathrm{NA}+\mathrm{Cho}+\mathrm{Cr})$ obtained in 39 male blood donors at low risk for HIV infection who had repeat MRS with a mean interscan interval of 11 months. ${ }^{19}$ The magnitude of the changes in $\mathrm{NA} /(\mathrm{NA}+\mathrm{Cho}+\mathrm{Cr})$ seen in all five patients in the present study are larger than this reported variation. Patient 5 did not improve clinically until five weeks after his final scan and the addition of 3TC (Lamivudine, GlaxoWellcome PLC, Beckenham, UK) to his treatment regimen. The spectroscopic changes in this patient occurred before evidence of clinical improvement and may reflect subclinical biochemical alteration. Inferred changes in NA signals may have been caused by alterations in concentrations, relaxation times, or both. Indeed, prolongation in the T2 of NA has previously been reported in HIV seropositive patients who had hyperintense white matter on T2 weighted imaging. ${ }^{20}$ However, such an increase in the T2 of NA would lead to a signal which would overestimate the concentration of metabolite present. Our spectroscopic findings suggest that alterations in the NA resonance (at long echo times) may not be entirely due to neuronal cell death and may possibly reflect reversible neuronal dysfunction. One possible explanation for the decrease and subsequent increase in the $\mathrm{Cho} / \mathrm{Cr}$ ratio seen as patients improved and deteriorated clinically is that changes in this ratio reflect changes in glial cell density due to inflammatory cell diminution followed by reinfiltration within the spectroscopic ROI.

Several studies have reported short term clinical benefits of zidovudine, especially in relation to the degree of HADC. ${ }^{21}{ }^{22}$ Nucleoside analogues such as zidovudine act by the competitive inhibition of the HIV enzyme reverse transcriptase, which is essential for replication of the virus. On commencing zidovudine there is an initial fall in plasma HIV-1 RNA concentrations, reaching maximum suppression in about seven days, followed by a return towards baseline concentrations within weeks. ${ }^{23}$ The timescale of these changes seems to be similar to the spectroscopic changes reported in this study. Combination therapy with 2 transcriptase inhibitors results both in a greater fall in plasma HIV-1 concentrations and improved clinical benefit than zidovudine monotherapy. ${ }^{24}$ Note that patient 5 only improved clinically after the addition of 3TC to his treatment regimen. Measuring changes in MRS could be very useful in assessing the potential clinical benefit of the new combination therapies in the treatment of HADC.

The second important finding in this study was that atrophy progressed despite the initial clinical improvement in all patients (excluding patient 4 in whom CSF/ICV only increased by a small amount). The reason for this is not apparent. Previous cross sectional studies have shown a strong relation between the presence of atrophy and HADC. ${ }^{72}$ It seems that loss of brain parenchyma is irreversible under the conditions of the present study even during clinical improvement in HADC. The changes in $\mathrm{CSF} / \mathrm{ICV}$ ratio seen in all but patient 4 were larger than the $4 \%$ coefficient of variation from repeat scans of a volunteer reported previously. $^{7}$

Changes in white/grey matter pixel intensity ratios only reflected the clinical changes at the time of scanning in two of five patients. Patient 1 showed a decrease in Cwg which lagged behind both the spectroscopic and clinical improvements. This apparent time lag indicates that spectroscopy may show abnormalities before those found on T2 weighted imaging. This finding is in agreement with an early report of spectroscopic abnormalities in 
HIV seropositive patients with normal white matter on MRI. ${ }^{8}$

Changes in the $\mathrm{NA} /(\mathrm{NA}+\mathrm{Cho}+\mathrm{Cr}), \mathrm{NA} /$ Cho, Cho/Cr, and CSF/ICV ratios and Cwg did not reflect the neurological improvement found in patient 4 . The NA:Cr ratio was the only MR marker that "improved" at the same time as the clinical status. However, all the pretreatment MR data were, except for the Cwg ratio, close to the mean of those from the control group. It is interesting that patient $4 \mathrm{had}$ the smallest overall increase in CSF:ICV ratio. Explanations for this anomaly include the possibility of a different aetiological agent being responsible for his initial Cwg and neurological abnormality. Unfortunately, this patient had neither CSF analysis nor necropsy. Recent data suggest that although white matter imaging abnormalities due to histopathologically established cytomegalovirus encephalitis and HIV leucoencephalopathy/encephalitis may be indistinguishable, ${ }^{26}$ the depletion in NA/Cho ratio in HIV leucoencephalopathy/ encephalitis may be greater than in cytomegalovirus encephalitis. ${ }^{27}$ The inference that different pathological processes could be involved may suggest a reason for different MR characteristics being seen in patient 4 .

Both spectroscopic and white/grey matter pixel intensity ratios reported in this study are region specific. Although in our experience, most HIV related white matter hyperintensity (on T2 weighted imaging) predominantly occurs at first in the parieto-occipital region (unpublished findings), in some cases abnormality can initially be found in the frontal lobes and can also occur within the brain stem. It would thus be advantageous if the spatial distributions of both the Cwg and spectroscopic metabolite ratios could be determined. Spectroscopic imaging has been performed on HIV positive patients in previous studies ${ }^{10} 28$ and could be implemented in the context of the present study, patient examination time permitting. The present method of quantifying the degree of white matter hyperintensity could be extended to produce, for example, contrast maps.

There is a definite clinical need for objective methods with which to monitor the neurological effects of antiretroviral therapy, both on an individual basis and on groups of subjects. Previous work has shown that it is logistically feasible to use MRI and spectroscopy in HIV related drug trials. ${ }^{30}$ The present data indicate that quantitative MRI and spectroscopy have a role in assessing the neurological effects of antiretroviral therapies in patients with AIDS. Combination therapies which contain more than one antiretroviral agent are undergoing trials and their neurological effects need to be monitored.

Funding was provided by grant number SPG 8915593 from the Medical Research Council of Great Britain. We are indebted to the radiographers of the Middlesex Hospital MRI Unit for their radiographic expertise.

1 Harrison MJG, McArthur JC. AIDS and neurology. London: Churchill Livingstone, 1995.

2 Olsen WL, Longo FM, Mills CM, Norman D. White matter disease in AIDS: findings at MR imaging. Radiology 1988; 169:445-8.
3 Dooneief G, Bello J, Todak G, et al. A prospective controlled study of magnetic resonance imaging of the brain in gay men and parenteral drug users with human immunodeficiency virus infection. Arch Neurol 1992;49:

4 Post MJD, Berger JR, Quencer RM. Asymptomatic and neurologically symptomatic HIV-seropositive individuals: prospective evaluation with cranial MR imaging. Radiology 1991;178:131-9.

5 Tozzi V, Narciso P, Galgani S, Sette P, Balestra P, Gerace C, et al. Effects of zidovudine in 30 patients with mild to end

6 Wilkinson ID, Chinn RJS, Paley MNJ, Hall-Craggs MA, Miller RF, Kendall BE, Harrison MJG. Sub-cortical whitegrey matter contrast on MRI as a quantitative marker for grey matter contrast on MRI as a quantitative marker for 1996;51:475-9.

7 Paley M, Chong W, Wilkinson ID, Shepherd JK, Clews A, Sweeney BJ, et al. Cerebrospinal fluid - Intracranial volume ratio measurements in patients with HIV infection: CLASS image analysis technique. Radiology 1994;190:879-86

8 Menon DK, Baudouin CJ, Tomlinson D, Hoyle C. Proton MR spectroscopy and imaging of the brain in AIDS: evidence of neuronal loss in regions that appear normal with imaging. F Comput Assist Tomogr 1990;14: $882-5$.

9 Chong WK, Sweeney B, Wilkinson ID, Paley M, HallCraggs MA, Kendall BE, et al. Proton spectroscopy of the brain in HIV infection: correlation with clinical, immunologic and MR imaging findings. Radiology 1993;188:11924 .

10 Meyerhoff DJ, MacKay S, Bachman L, Poole N, Dillon WP, Weiner MW, Fein G. Reduced brain N-acetylaspartate suggests neuronal loss in cognitively impaired human immunodeficiency virus-seropositive individuals: in-vivo $\mathrm{H}$ magnetic resonance spectroscopic imaging. Neurology 1993;43: 509-15

11 Paley M, Wilkinson ID, Hall-Craggs MA, Chong WK, Chinn RJS, Harrison MJG. Short echo time proton spectroscopy of the brain in HIV infection / AIDS. Magn Reson Imaging 1995;13:871-5.

12 Jarvick JG, Lenkinski RE, Grossman RI, Frank I, Ramer $\mathrm{KN}$. Proton MR spectroscopy in HIV-infected patients: characterization of abnormalities with imaging and clinical correlation. Radiology 1993;186:739-44.

13 Everall IP, Luthert PJ, Lantos PL. Neuronal loss in the frontal cortex in HIV infection. Lancet 1991;337: the frontal

14 Wilkinson ID, Hall-Craggs MA, Chong WK, Paley M, Noble P, Harrison MJG, Weller IVD. Increase in NA/Cr metabolite ratio following anti-retroviral drug therapy in AIDS: a case study. In: Book of abstracts: 12 th Annual MeetAIDS: a case study. In: Book of abstracts: 12th Annual Meet-
ing of the Society of Magnetic Resonance in Medicine. Vol 3. ing of the Society of Magnetic Reson

15 Vion-Dury J, Nicoli F, Salvan A, Confort-Gouny S, Dhiver C, Cozzone PJ. Reversal of brain metabolic alterations with zidovudine detected by proton localised magnetic resonsnce spectroscopy. Lancet 1995;345:60-1.

16 Report of a Working Group of the American Academy of Neurology AIDS Task Force. Nomenclature and research case definitions for neurologic manifestations of human immunodeficiency virus-type 1 (HIV-1) infection. Neurology 1991;41:778-85.

17 CDC. Revised classification system for HIV infection and expanded case definitions for AIDS among adolescents and adults. $M M W R$ 1992;41:1-19.

18 Fox JD, Brink NS, Zuckerman MA, et al. Detection of herpesvirus DNA by nested polymerase chain reaction in cerebrospinal fluid of human immunodeficiency virusinfected persons with neurologic disease: a prospective evaluation. F Infect Dis 1995;172:1087-90.

19 Wilkinson ID, Chinn RJS, Paley M, Sweeney B, Maloney MA, Chong WK, et al. Serial proton spectroscopy of brain parenchyma in HIV infection. In: Book of abstracts: Second Meeting of the Society of Magnetic Resonance. Vol 2. Berkeley CA: SMR, 1994:582.

20 Wilkinson ID, Paley M, Chong WK, Sweeney B, Shepherd $\mathrm{JK}$, Kendall BE, et al. Proton spectroscopy in HIV infection: relaxation times of cerebral metabolites. Magn Reson Imaging 1994;12:951-7.

21 Yarchoan R, Berg G, Brouwers P, Fischl MA, Spitzer AR, Wichman A, et al. Response of human-immunodeficiency-deoxythimidine. Lancet 1987;i:132-5.

22 Schmitt FA, Bigley JW, McKinnis R, Logue PE, Evans RW, Druckner JL, The AZT collaborative working group. Neuropsychological outcome of Zidovudine (AZT) treatment of patients with AIDS and AIDS-related complex. N Englf Med 1988;319:1573-8.

23 Loveday C, Kaye S, Tenant-Flowers M, Semple M, Ayliffe U, Weller IVD, Tedder RS. HIV-1 RNA serum-load and resistant viral genotypes during early zidovudine therapy. Lancet 1995;345:820-4.

24 Yeni P, on behalf of the European / Australian Delta trial: based on data up to 31 May 1995. 5th European congress on September, 1995.

25 Dal Pan GJ, McArthur JH, Aylward E, Selnes OA, Nance-Sproson TA, Kumar AJ, Mellits ED, McArthur JA. Patterns of cerebral atrophy in HIV-1 - infected individuals: results of a quantitative MRI analysis. Neurology 1992;42: 2125-30. 
26 Miller RF, Lucas SB, Hall-Craggs M, Brink NS, Scaravilli F, Chinn RJS, et al. A comparison of MR imaging and CSF analysis with neurop HIV and CMV associated CNS disease in AIDS. fournal of Neurovirology 1996;2:44

27 Wilkinson ID, Miller RF, Paley MNJ, Miszkiel KA, Kendall BE, Hall-Craggs MA, Harrison MJG. Cerebral proton magnetic resonance spectroscopy in cytomegalovirus encephalitis and HIV leucoencephalopathy/encephalitis. AIDS 1996;10:1443-4.

28 Meyerhoff DJ, MacKay S, Poole N, Dillon WP, Weiner MW, Fein G. N-acetylaspartate reductions measured by $1 \mathrm{H}$
MRSI in cognitively impaired HIV-seropositive individuals. Magn Reson Imaging 1994;12:653-9.

29 Barker PB, Lee RR, McArthur J. AIDS dementia complex: evaluation with proton MR spectroscopic imaging. Radiology 1995;195:58-64.

30 Hall-Craggs MA, Williams I, Wilkinson ID, Paley MNJ, Chinn RJS, Weller IVD, et al. Proton spectroscopy in a cross-section of HIV positive asymptomatic patients receiving immediate compared with deferred patients receiving immediate compared with deferred
zidovudine (concorde study). $\mathcal{F}$ Neuro-AIDS 1996:1:10313. 